\title{
Adolescência e aids: avaliação de uma experiência de educação preventiva entre pares*
}

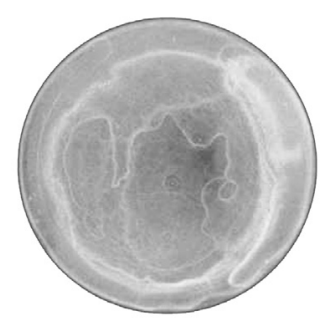

\author{
José Ricardo de Carvalho Mesquita Ayres ${ }^{1}$ \\ Angela Carvalho Freitas ${ }^{2}$ \\ Marco Antonio Silva dos Santos ${ }^{3}$ \\ Haraldo César Saletti Filho ${ }^{4}$ \\ Ivan França Júnior ${ }^{5}$
}

AYRES, J. R. C. M. Adolescence and Aids: evaluation of a preventive education experience among peers, Interface - Comunic, Saúde, Educ, v.7, n.12, p.113-28, 2003.

Preventive HIV/AIDS actions focusing on overcoming the limitations of interventions of a behavioral nature and incorporating concerns with the socio-cultural determinants of these behaviors currently constitute both a necessity and a gap. This article deals with a study on prevention in the school environment based on a strategy of reducing vulnerability. It is a qualitative and quantitative case study that, within the context of this strategy, evaluates the sida prevention work carried out by students who function as multiplying agents in a public high school in the outskirts of the city of São Paulo. The following stands out in the results: the effectiveness of the proposal, broadly accepted and favorably absorbed by the school's students; the diversified profile of voluntary students acting as multiplying agents; and the tension between the cognitive-behavioral model and the socialconstructivist model in the educational processes concretely operated by the multiplying agents. The article concludes that there is a possibility and interest in the action of students acting as multiplying agents from the standpoint of the strategies of reduction of vulnerability. It also points out the need to develop mechanisms for the recruitment and training of agents capable of problematizing and overcoming the said tension.

KEY WORDS: Sida; prevention; school; vulnerability; adolescence; evaluation.

Ações preventivas de HIV/AIDS, orientadas à superação dos limites das intervenções de corte comportamentalista, incorporando preocupações com os determinantes sócio-culturais desses comportamentos, constituem hoje uma necessidade e, ao mesmo tempo, uma lacuna. O presente artigo trata de estudo de prevenção no ambiente escolar baseado em estratégia de redução de vulnerabilidade. Constitui um estudo de caso, de corte quanti-quali, que, no contexto desta estratégia, avalia o trabalho de prevenção de aids desenvolvido por alunos multiplicadores em uma escola estadual de ensino médio na periferia da cidade de São Paulo. Entre os resultados, destacam-se: a efetividade da proposta, com ampla aceitação e favorável aproveitamento pelos alunos da escola; o perfil diversificado do aluno multiplicador voluntário; e a tensão entre modelos cognitivo-comportamentalistas e social-construtivistas nos processos educativos concretamente operados pelos multiplicadores. Conclui-se pela possibilidade e interesse da ação de alunos multiplicadores na perspectiva das estratégias de redução de vulnerabilidade, apontando-se a necessidade de desenvolver mecanismos de captação e capacitação capazes de problematizar e superar a tensão apontada.

PALAVRAS-CHAVE: Aids; prevenção; escola; vulnerabilidade; adolescência; avaliação.

\footnotetext{
* Projeto financiado por: CNPq, Fapesp e MacArthur Foundation.

${ }^{1}$ Professor Associado, Departamento de Medicina Preventiva da Faculdade de Medicina, Universidade de São Paulo/USP.<jrcayres@usp.br>

${ }^{2}$ Médica residente, Departamento de Doenças Infecciosas e Parasitárias, Faculdade de Medicina da USP. <angelacf@uol.com.br>

${ }^{3}$ Médico residente, Departamento de Medicina Geral e Comunitária, Universidade Federal do Rio Grande do Sul. $<$ marcoantonios@hotmail.com>

${ }^{4}$ Médico residente, Departamento de Medicina Preventiva, Faculdade de Medicina da USP. <cesar.saletti@bol.com.br>

${ }^{5}$ Professor, Departamento de Saúde Materno Infantil, Faculdade de Saúde Pública da USP. <ifjunior@usp.br>
} 


\section{Introdução}

As propostas de prevenção de Aids entre jovens podem ser agrupadas em dois blocos: um, centrado na transmissão da informação, visa fundamentalmente à modificação de comportamentos de risco (DiClemente, 1992; Moore et al., 1996); outro, mais recente e uma espécie de reação àquele, enfatiza as condições culturais, econômicas, políticas e morais que estão na base dos comportamentos de risco, buscando produzir uma resposta social capaz de transformar os contextos favorecedores de tais comportamentos (Paiva, 2000; Fonseca, 2002). Estes dois pólos configuram abordagens bastante diversas quanto a objetivos, estratégias e critérios de avaliação.

Quando a ênfase recai no binômio informação-comportamento, a característica dominante nos trabalhos é a proposição de um processo educativo modelador, sendo o resultado a ser alcançado tido como passível de ser previamente determinado, por meios técnico-científicos. Nas ações desenvolvidas no ambiente escolar, a responsabilidade de transmissão da informação é atribuída a técnicos, profissionais da Educação ou da Saúde, ou pode ser transferida para os próprios alunos (peer educators, multiplicadores), o que tem sido fortemente recomendado na produção com esse perfil (Darroch et al., 2000; Fernández Costa et al., 1999; Gao et al., 2001; Hovell et al., 1998; Kirby et al., 1994; Kirby et al., 1997; Rickert et al., 1991; Schort, 1998).

Uma série de aspectos relevantes pode ser apreendida na revisão crítica dessa literatura. Em primeiro lugar, a reflexão sobre a identidade da coletividade escolar é quase sempre negligenciada, os dados de caracterização sócio-cultural são pobres e há tímidas inferências sobre o potencial local para enfrentamento da epidemia da aids. A abordagem do tema não é transversal; o conhecimento é transmitido em unidades que são adicionadas a determinadas disciplinas curriculares; os professores são vistos como técnicos que devem saber transmitir as informações necessárias à mudança de comportamento dos jovens, conforme manuais de orientação que ensinam o conteúdo e a estratégia a serem adotados em sala de aula; os professores/técnicos devem estimular os alunos a assimilarem as informações e, para isso, oferecem certificados e vinculam a educação preventiva a trabalhos escolares, com gratificações por notas.

Há, nessa literatura, suspeita de que a discussão de temáticas sobre prevenção de DST/AIDS e métodos contraceptivos provoque o início mais "precoce" da atividade sexual e aumento do número de relações. Em artigos de revisão, não há qualquer evidência convincente desta relação, muito ao contrário. Entretanto, a abstinência avança como discurso preponderante e muitas vezes exclusivo. Comparando-se 1988 e 1999, 2\% e 23\%, respectivamente, dos professores de escolas públicas (high school) consideram a abstinência a única via recomendável de prevenção. Acompanhando esse movimento, houve também uma sensível redução na discussão de métodos contraceptivos nas escolas. Alguns professores chegam mesmo a questionar a eficácia do preservativo na proteção contra as DST e o conteúdo de educação sexual nas salas de aula vem sofrendo evidente empobrecimento. O discurso dessas propostas tem acabado, desta forma, por deslocar-se da preocupação com o controle dos comportamentos sexuais de risco para o controle do risco de comportamentos sexuais.

Entre as dificuldades encontradas no trabalho de prevenção, os professores 
apontam como a maior delas o desinteresse dos alunos, superando em importância a insuficiência de tempo e a falta de material pedagógico adequado. Mesmo os laços construídos pelos jovens são percebidos apenas na perspectiva de superação de resistências ao conteúdo informativo. A realização de intervenções por pares acontece pela necessidade de mediar a informação intragrupo, permitindo a identificação dos jovens com o tema em discussão $e$ contornando eventuais barreiras culturais locais. Não há, nesse caso, diferença entre peers-led ou adults-led information: nos dois casos o que interessa é que a mensagem seja adequadamente carreada no que se refere à alteração de conhecimento $e$ atitudes.

No outro pólo das propostas preventivas, vêm surgindo trabalhos que, especialmente a partir da discussão sobre vulnerabilidade (Mann \& Tarantola, 1996; Mann et al., 1993; Parker, 2000), propõem ações não restritas ao componente informação, buscando trabalhar com aspectos mais estruturais ou contextuais que determinam a exposição ao HIV.

$O$ desenvolvimento do conceito de vulnerabilidade ao HIV/AIDS pode ser descrito, em linhas gerais, como um esforço de produção e difusão de conhecimento, debate e ação sobre os diferentes graus e naturezas de suscetibilidade de indivíduos e coletividades à infecção, adoecimento e morte pelo HIV, segundo particularidades formadas pelo conjunto dos aspectos sociais, programáticos $e$ individuais que os põem em relação com o problema $e$ com os recursos para seu enfrentamento.

No plano individual, a avaliação de vulnerabilidade ocupa-se, basicamente, dos comportamentos que criam a oportunidade de infectar-se e/ou adoecer, nas diversas situações já conhecidas de transmissão do HIV (relação sexual, uso de drogas injetáveis, transfusão sangüínea e transmissão vertical). Considera, entretanto, que os comportamentos associados a maior chance de exposição à infecção, adoecimento ou morte não podem ser entendidos como decorrência imediata e exclusiva da vontade dos indivíduos, mas relacionam-se ao grau de consciência que esses indivíduos têm dos possíveis danos decorrentes de tais comportamentos e, especialmente, ao poder de transformação efetiva de comportamentos a partir dessa consciência.

Essas diferentes possibilidades de os indivíduos obterem informações $e$ fazerem efetivo uso delas já remete ao segundo plano das análises de vulnerabilidade: o social. No plano social, a vulnerabilidade vem sendo avaliada em termos dos seguintes aspectos: a) acesso à informação; b) quantidade de recursos destinados à saúde por parte das autoridades e legislação locais; c) acesso e qualidade dos serviços de saúde; d) nível geral de saúde da população, mediante comportamento de indicadores de saúde, como o coeficiente de

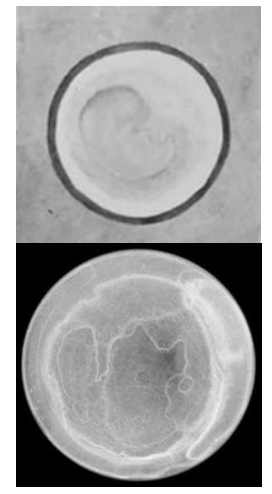
mortalidade infantil; e) aspectos sócio-políticos e culturais de segmentos populacionais específicos, como a situação da mulher (menores salários, ausência de legislações de proteção específica, exposição à violência; restrições de exercício de cidadania etc.); f) grau de liberdade de pensamento e expressão, sendo tanto maior a vulnerabilidade quanto menor a possibilidade desses sujeitos fazerem ouvir suas necessidades nas diversas esferas decisórias; g) grau de prioridade política (e econômica) dada à saúde; h) condições de bem-estar social, como moradia, escolarização, acesso a bens de consumo, entre outros. 
Por fim, conectando o plano individual e o social, está o plano programático, pois a vulnerabilidade de cada indivíduo está diretamente relacionada ao modo como os serviços de saúde e os demais serviços sociais, com destaque aqui para a educação, permitem que, em contextos determinados, se mobilizem os recursos ali necessários para a proteção das pessoas à infecção e ao adoecimento pelo HIV. O plano programático referese, portanto, à existência de ações institucionais especificamente voltadas para o problema da aids, e a vulnerabilidade é apreendida aqui por aspectos como: a) grau e tipo de compromisso das autoridades locais com o enfrentamento do problema; b) ações efetivamente propostas por estas autoridades; c) coalizão inter-institucional e inter-setorial (saúde, educação, bem-estar social, trabalho etc.) para atuação específica; d) planejamento das ações; e) gerenciamento dessas ações; f) capacidade de resposta das instituições envolvidas; g) financiamento adequado e estável dos programas propostos; h) sustentabilidade das ações; i) avaliação $e$ retroalimentação dos programas, entre outras possibilidades.

A lógica da vulnerabilidade, ao buscar produzir essas sínteses particularizadoras da diversidade e complexidade das situações de suscetibilidade coletiva, ao basear-se, para isso, em enfoques necessariamente interdisciplinares e intersetoriais e ao articular em suas construções conceituais elementos estritamente técnicos a outros radicalmente sociais e políticos, tende a colaborar para que os elementos sociais, econômicos, culturais, políticos e éticos da prevenção passem do pano de fundo a que os relega os enfoques comportamentalistas para o plano das ações concretas, sendo eles próprios objetos de intervenção. Experiências práticas de utilização dessa referência no desenvolvimento de ações preventivas no ambiente escolar são ainda relativamente recentes $e$ a literatura sobre seus resultados, escassa. É no sentido de contribuir para o preenchimento dessa lacuna que se insere o presente trabalho.

\section{Objetivo}

Considerando a relevância e especificidade do trabalho com jovens na dinâmica da epidemia de HIV/AIDS e as novas perspectivas abertas pelo conceito de vulnerabilidade, foi proposto um projeto de intervenção $e$ pesquisa com o objetivo de elaborar e avaliar uma estratégia de prevenção de Aids entre escolares, que trabalhasse de modo abrangente e integrado os aspectos individuais, sociais e programáticos que tornam esse segmento populacional vulnerável à infecção e adoecimento pelo HIV.

No presente artigo, vamos nos ater a um aspecto processual da estratégia desenvolvida: as ações de educação preventiva entre pares. Nesse sentido, o objetivo é avaliar a efetividade de uma estratégia de educação preventiva entre pares no ambiente escolar, com vistas à redução da vulnerabilidade ao HIV/AIDS.

\section{Metodologia}

Trata-se de "investigação avaliativa" (Novaes, 2000; Nemes, 2001) na forma de estudo de caso, combinando metodologia quantitativa e qualitativa, fundamentada nos trabalhos de Mann et al. (1993) e estudos posteriores de Ayres (1996a, 1996b, 1998) e Ayres et al. (1999). O norte para a intervenção preventiva na escola foi estimular uma resposta social e não 
apenas trabalhar com a idéia restrita de mudança de comportamento.

Elegeu-se como campo da pesquisa a Escola Estadual de Segundo Grau Virgília Rodrigues Alves de Carvalho Pinto (Virgília), localizada no Parque Previdência, periferia oeste da cidade de São Paulo, com 1.200 alunos, de ambos os sexos, moradores na região e adjacências. A escola atende jovens com idade entre 14 e 18 anos, em sua maioria provenientes de camadas de média e baixa renda da zona oeste da cidade.

No início do projeto, no segundo semestre de 1997, foram feitas reuniões com o corpo docente e alunos voluntariamente interessados em participar de trabalhos preventivos, nos quais foram debatidos os princípios e temas norteadores de uma estratégia de redução de vulnerabilidade. A essa primeira aproximação seguiu-se uma investigação de natureza qualitativa, que consistiu em uma série de entrevistas com professores e observação participante em grupos de discussão com os alunos, resultando no seguinte diagnóstico:

\begin{tabular}{|c|c|c|c|}
\hline Fonte & Individual & Social & Programático \\
\hline Professores & $\begin{array}{l}\text { sensação de } \\
\text { invulnerabilidade }\end{array}$ & $\begin{array}{c}\text { "desobrigação" dos pais } \\
\text { proximidade do "futuro" - falta } \\
\text { de perspectivas } \\
\text { exposição ao mercado das } \\
\text { drogas }\end{array}$ & $\begin{array}{c}\text { falta de "autoridade" da escola para } \\
\text { prevenção } \\
\text { estrutura muito voltada para a } \\
\text { educação formal } \\
\text { carência de recursos para uma } \\
\text { pedagogia mais ampla }\end{array}$ \\
\hline Alunos & $\begin{array}{l}\text { muita "cerimônia" com o } \\
\text { tema } \\
\text { cabeça no futuro: } \\
\text { insegurança } \\
\text { drogas: necessidade } \\
\text { de "se enturmar" }\end{array}$ & & $\begin{array}{l}\text { pouco espaço de participação } \\
\text { dos alunos } \\
\text { falta de acesso a camisinhas }\end{array}$ \\
\hline Observação & $\begin{array}{l}\text { visão muito individual do } \\
\text { problema }\end{array}$ & $\begin{array}{l}\text { carência de suporte familiar e } \\
\text { social }\end{array}$ & $\begin{array}{l}\text { insegurança do quadro docente } \\
\text { sobre o assunto } \\
\text { heterogeneidade dos alunos, pouca } \\
\text { integração comunitária } \\
\text { descostura de um projeto "formativo" } \\
\text { carência de espaços de } \\
\text { representação discente }\end{array}$ \\
\hline
\end{tabular}

A partir deste diagnóstico, foram propostas diretrizes e estratégias para o trabalho de intervenção: 1 estimular o protagonismo, colocando os alunos no centro do desenvolvimento das estratégias preventivas da escola; 2 estimular a percepção do problema e atuação sobre ele a partir de uma perspectiva reflexiva $e$ atenta à comunidade de origem $e$ de destino dos alunos; 3 articular a estratégia de prevenção a projetos mais amplos de pedagogia e de inserção social desses jovens.

Apoiados nesses princípios, foram definidos objetivos e atividades para o projeto de ação preventiva: 1 promoção de reflexão, debate $e$ posicionamento ativo sobre o problema-alvo (trabalhado com 
multiplicadores em oficinas de sexo seguro, gravidez e prevenção do uso abusivo de drogas); 2 estímulo à resposta grupal diante do problema-alvo (planejamento e realização de atividades de mobilização interna/externa; apoio à reestruturação do grêmio estudantil); 3 facilitação do acesso a recursos programáticos para cuidados de saúde (retaguarda para aconselhamento, testagem e fornecimento de camisinha); 4 incremento da integração/suporte comunitários (orientação vocacional; rede de empregos; atividades dirigidas aos pais); 5 enriquecimento do projeto pedagógico (apoio para temas transversais na perspectiva do problema-alvo e questões de saúde e direitos humanos; parceria para um projeto formador; atividades de apoio sobre o problema-alvo para os professores).

Para atingir esses objetivos, especialmente o primeiro e segundo, foi formado um grupo de alunos multiplicadores (AM), cerca de vinte, que participaram de oficinas de capacitação sobre os temas: adolescência, sexualidade, Aids, DST, contracepção, gravidez, drogas, cidadania, relações de gênero, discriminação, estigma e a própria noção de vulnerabilidade. Em períodos determinados os AM vão às salas de aula e conduzem oficinas com seus pares. Além dessas tarefas nucleares, desenvolvem atividades como gincanas, feiras científicas e artísticas, mapeamento de equipamentos de saúde na região e eventos extra-muros.

Para o monitoramento e avaliação do trabalho dos multiplicadores foram utilizados dois protocolos: 1 questionário multiplicação (QM), com objetivo de avaliar a atuação dos alunos multiplicadores pelos demais alunos, aplicado a todos os alunos da escola; 2 entrevista multiplicador (EM), para auto-avaliação dos alunos multiplicadores, utilizada em amostra intencional de alunos multiplicadores.

Composto de questões fechadas e semi-abertas, o QM nasceu da necessidade de conhecer melhor os efeitos do projeto de redução de vulnerabilidade desenvolvido na escola, na perspectiva de avaliar o diálogo que está (ou não) se estabelecendo entre os alunos multiplicadores e seus pares e a recepção do conjunto dos alunos às atividades do multiplicador. Nesse sentido, o instrumento verificou a capacidade de o aluno identificar os colegas multiplicadores; sua compreensão acerca dos objetivos e meios do trabalho dos AM; o perfil que traça desses colegas quanto a características pessoais e escolares; o interesse ou não de ser, ele próprio, um multiplicador $e$ a avaliação das atividades de multiplicação das quais participou, no que se refere a seu desenvolvimento e resultados.

A aplicação do questionário foi feita em dezembro de 2000, cobrindo os diversos turnos em um único dia, sem aviso prévio, com a paralisação de um período de aula para este fim ${ }^{6}$.

A EM objetivou avaliar a atividade de multiplicação sob a perspectiva do multiplicador, por meio de um estudo qualitativo que utilizou entrevistas em profundidade, gravadas e posteriormente transcritas.

A eleição dos participantes foi feita a partir de um levantamento dos multiplicadores e ex-multiplicadores do Virgília. Entre os localizados, foram escolhidos aqueles que se destacavam por sua capacidade de expressão, experiência e representatividade do perfil médio dos multiplicadores.

Foram realizadas 13 entrevistas, doze em dois encontros, e uma para a qual foram necessários três encontros. Os primeiros encontros duraram, em média, uma hora e meia e os segundos, meia hora.
${ }^{6}$ Foi garantido o sigilo dos dados individuais de cada questionário, sendo esclarecido que não se queria, nem poderia, identificar os autores das respostas. Não houve recusa em participar, apenas os alunos multiplicadores foram convidados a se abster de responder o questionário. 


\section{Resultados e discussão}

Os multiplicadores por seus pares

Dos 1125 alunos matriculados na escola, 721 responderam o $\mathrm{QM}$, excetuando-se

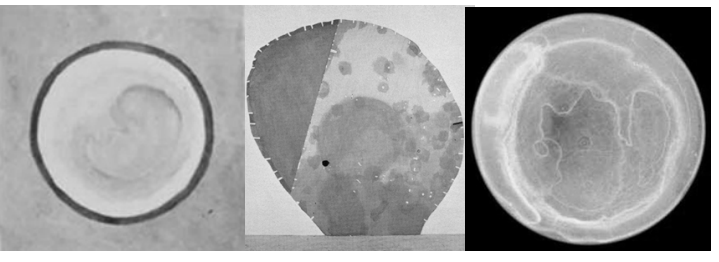

cincoenta alunos de uma turma do $2^{\circ}$ ano do ensino médio, submetida a um teste piloto do questionário. Dos que responderam, $51,3 \%$ eram mulheres $e$ $48,7 \%$ do sexo masculino. A idade média foi de 17 anos, com extremos entre 14 e 36 anos. Quanto à religião, 171 não responderam (maior abstenção de respostas) e, entre os que responderam, houve amplo predomínio dos católicos $(73,3 \%)$. Quanto à distribuição por turma, $66,5 \%$ eram alunos de primeiro ano; $55,9 \%$ de segundo ano; e $69 \%$ de terceiro ano, distribuição relativamente proporcional, com discreto decréscimo na segunda série em função da exclusão da turma piloto. A mesma relativa proporcionalidade pôde ser verificada na distribuição por turno: $36,1 \%$ da manhã; $33,2 \%$ da tarde; e $30 \%$ da noite (o decréscimo observado no turno da manhã é devido à exclusão da turma piloto $e$ no noturno, pelo maior absenteísmo normalmente apresentado).

Para ponderar a validade da opinião dos alunos sobre a multiplicação, perguntamos o ano de ingresso na escola, considerado para a análise do tempo de contato com as atividades de multiplicação: $99,6 \%$ dos alunos tiveram pelo menos um ano de contato com o programa e 66,1\% acompanharam os dois últimos e mais intensos anos de intervenção na escola.

Quando questionados se sabiam da existência de um grupo de alunos multiplicadores na escola, apenas três alunos não responderam e, dos que responderam, $91 \%$ conheciam o grupo. Destes, $86 \%$ já haviam participado de alguma atividade de multiplicação, ou seja: a maioria estava "autorizada" a emitir opinião sobre o programa.

Questionados se os colegas multiplicadores inspiravam confiança, $81,3 \%$ responderam sim, e 18,7\%, não, justificando a resposta com argumentos como: não gostar pessoalmente; não conhecer; achar que os AM não mantêm sigilo sobre o que os colegas falam nas multiplicações; não confiar, simplesmente; $e$ julgar que os multiplicadores não entendem sobre os temas das oficinas ou não têm seriedade ao discuti-los.

Sobre a natureza do trabalho dos multiplicadores, $72 \%$ responderam conhecer $e$, em pergunta aberta, mencionaram temas $e$ atividades trabalhados: prevenção à DST/AIDS (71,2\%); sexualidade (34,2\%); importância da camisinha (33,3\%); palestras (22,3\%); drogas (18,4\%); violência $(0,2 \%)$; gincana Solidariedaids $(5,5 \%)$. Vê-se aqui, clara identificação dos multiplicadores às DST/AIDS, embora o projeto na escola tenha envolvido, também, a questão das drogas e da gravidez. Muitos chegaram até a localizar especificamente na camisinha a identidade do multiplicador.

Seguimos perguntando sobre o tipo de ganho que cada um julgou ter alcançado nas oficinas. Dos 636 alunos que responderam a esta pergunta, $50 \%$ disseram que o maior ganho foi "discutir sobre os temas"; $30 \%$ indicaram "receber informações"; e 20\% "tirar dúvidas". Foi bastante motivador verificar que a maior parte dos alunos identificou a possibilidade de discutir os temas como o principal ganho desse espaço, uma vez que é esta a tarefa dos multiplicadores no contexto de uma estratégia de redução de vulnerabilidade.

Em outra questão aberta, os alunos foram estimulados a exemplificar os ganhos que tiveram nas oficinas $e$, mais uma vez, as respostas misturaram 
temas, atitudes, práticas e questões contextuais, como prevenção às DST e aids; sexualidade; como usar a camisinha; drogas; sexualidade e violência; respeito ao portador do HIV e aborto.

Sobre a opinião acerca das oficinas, questão respondida por 712 alunos, constatou-se altíssimo grau de aprovação: 94\% consideraram as multiplicações "um bom jeito de conversar"; para 3,8\% as oficinas "não são um bom jeito de conversar"; e 2,2\% disseram "não gostar de conversar esses assuntos".

Para além dessa aceitação, era importante saber que tipo de interação estava ocorrendo nas oficinas (diálogo, pedra de toque da construção de respostas sociais ou simples transmissão de informação?). O debate foi a vivência da grande maioria (89\% de 607 que responderam).

Buscando saber se no espaço das oficinas foram criadas condições adequadas para que os alunos se sentissem à vontade para participar dos debates, questionamos sobre impressões mais pessoais. Analisando as 606 respostas, observou-se que, apesar de a maioria se sentir à vontade para emitir suas opiniões $(76,4 \%)$, uma incômoda porcentagem de alunos não o consegue $(23,6 \%)$, o que exige refletir sobre a dinâmica da atividade.

Outra aproximação pela via da subjetividade foi a tentativa de identificar o tipo de apelo que a função de multiplicador exercia sobre os alunos. Ao serem questionados se gostariam de ser alunos multiplicadores, 47,5\% responderam que não sabiam; $21,5 \%$ responderam que gostariam (destes $17,5 \%$ disseram não ser possível por falta de tempo); e o restante respondeu que não gostaria, por diversas razões. Esses dados apontam uma posição bastante reticente, levando a se pensar numa possível carência de legitimidade do papel do multiplicador, que cerca de $80 \%$ não querem ou não podem encarnar. A questão seguinte, no entanto, veio dissipar um pouco essa impressão, ao apontar a preferência que os jovens dão a seus pares na condução das atividades de prevenção: dos 676 que responderam, 56,6\% preferem que "alunos da escola" conduzam as atividades; $11,9 \%$ preferem "alunos de fora"; $8,3 \%$, "professores da escola"; e 23,1\%, "adultos de fora".

\section{Os multiplicadores pelos multiplicadores}

Os multiplicadores do Virgília não são um segmento particular dentro da escola, não podem ser considerados uma "tribo", nem provenientes de uma mesma "tribo". Eles próprios se definiram como pessoas que transitam por grupos diferentes:

\footnotetext{
Oh, eu tenho o meu estilo, converso até com bastante gente da escola: skatistas, aqueles... como eles chamam? Nerds, tem os maconheiros... eu conversava com todos, eu não tenho essa de fulano se veste assim, então não anda comigo. Eu não... (AM.8)
}

Talvez o primeiro traço comum que chama a atenção em meio à enorme diversidade de perfis demonstrada nos depoimentos é o valor da informação. Esta valorização permeia o discurso dos multiplicadores de forma uníssona. $O$ multiplicador se mostra seduzido pela informação, enxerga nela uma ferramenta da maior importância para enfrentar um mundo que o tempo todo traz novos desafios. A busca por informação esteve na raiz da adesão dos entrevistados ao papel de multiplicador: 
Um dos fatores, tipo, eu sempre gostei de aprender de tudo, sabe? Eu acho que a pessoa não pode ficar trancada naquele mundinho obscuro. Acho que você tem que ir em busca de todos os conhecimentos necessários pra você. -...- não tá sempre disponível em todos os lugares pra você, então vai ter no meu colégio, é um horário que tá disponível pra mim aprender alguma coisa, que ainda vai me trazer algum lucro... (AM.2)

Mas, se os multiplicadores afirmaram que o principal ganho de exercer este papel é a informação que obtêm para si, também deixaram claro que ser reconhecido pelos pares por ser veículo de informação é também um ganho valioso.

Cê quer ver eu ficar toda orgulhosa é quando alguém vem perguntar alguma coisa pra você, sabe? (AM.7)

Outro traço destacado entre os AM entrevistados é a valorização ou preocupação com a comunicação interpessoal. Isto é, alguns multiplicadores buscaram a atividade como forma de responder a uma necessidade de se comunicar, de falar livremente, conversar com pessoas novas, enfim: se expressar. Outros buscaram no espaço da multiplicação uma chance de superar uma dificuldade nessa esfera.

... eu não gosto de ficar isolada de ninguém, isso me faz muito mal, acho que eu sempre tenho que tá conversando com alguém, sempre tá ... assim, com um grupo de pessoas sempre conversando, né? Por isso que a oficina me faz falta, né? Porque, nossa, eu fico isolada assim, às vezes eu começo a chorar em casa assim, eu falo assim: “Ai meu Deus do céu, a escola faz muita falta, é muito ruim ficar sem, sei lá, a galera, sem se comunicar. (AM.10)

Não. -...- Eu tinha [dificuldade de falar em público] (risos). Acho que foi esse um dos motivos pra eu entrar pra oficina, sabe? Nossa, antes eu falar em público, eu ficava toda vermelha, -...- sabe? Aí eu falei: “Não, eu tenho que dar um jeito nisso, não dá. Entrei na oficina, entrei no grêmio, entrei na comissão de formatura, entrei na APM. Tudo o que era relacionado a público assim eu entrei. E eu perdi isso. (AM.9)

Perguntados sobre o que gostam de fazer, de que forma ocupam seus momentos de lazer, surgiram perfis até polarmente opostos:

"Eu não faço nada, moro com os meus pais... minha vida é meio pacata, sabe? Eu estudo de manhã, chega à tarde eu não faço nada... $\mathrm{O}$ quê mais? Faço curso de inglês. O quê mais? Gosto de estudar um pouquinho, um pouquinho, mas gosto, já é alguma coisa, gosto de ler bastante..." (AM.7)

Ah, sair na noite, curtir, jogar um futebolzinho de fim-de-semana, um voleibol... jogar uma sinuquinha, um baralho, vídeo game, computador, tocar violão muito, muito... Só também.(...) ...vai 
sempre eu e um amigo meu, que a gente se conhece desde pequeno assim, e a gente sempre vai pras casas noturnas que a gente faz um certo que um trabalho com a organização das casas.(...) ... à noite a gente tem passagem livre lá, tem consumação livre pra gente também. A gente vai lá, come alguma coisinha no restaurante lá do Elemento ...fica lá na ala Vip... dança, vai atrás de mulheres, zoa um pouco, toma uma cerveja, um whisky.... Depois vai pra casa, dorme até duas horas da tarde como hoje. (AM.12)

Sobre sexo e drogas, temas centrais da ação dos multiplicadores, surgiram posicionamentos bastante diversos, algumas vezes conflitantes:

Bom, eu não tenho nada contra porque cada cabeça é o seu guia, entendeu? Eu acho que deveria rolar, tipo meio que um respeito com os outros. (...) ninguém é obrigado a sentir o cheiro da maconha aqui, entendeu?(...) Eu fumei acho que durante... um ano. (AM.12)

Eu acho que é a melhor turma de todas, porque ninguém bebe, ninguém fuma, todo o mundo curte numa boa (...) Porque é um pessoal saudável. (...) eu não sei o que é usar uma droga, não sei nem direito distinguir o que é realmente, porque eu não tenho conhecimento. (AM.9)

De forma bastante homogênea, os multiplicadores tiveram dificuldade de reconhecer a escola como espaço qualificado para intervir na sua formação:

Bom, na honestidade mesmo eu acho que a escola precisa passar por mais mudanças (...) a única coisa na minha opinião que salva ainda é alguns professores, porque alguns professores também acham que não estão capacitados pra nos dar aula, (...) os materiais são bem precários (...) a gente tem laboratório, tem sala de vídeo mas nunca é usado. (...) os alunos, todo mundo acha um lixo a escola, num modo de ver assim: 'Puta, a escola é um lixo, ainda bem que eu vou passar no final do ano e acabou, mais nada". (AM.2)

Em diversos momentos a escola foi colocada como negligente, seja em relação à melhoria das condições do ensino, seja quanto ao cumprimento das normas e incentivo às atividades dos alunos. A negligência é marcante em relação às drogas, considerado por muitos multiplicadores entrevistados um problema importante da escola. Apesar da impressão geral desfavorável, os alunos tiveram uma percepção positiva do trabalho de multiplicação.

... sempre tem os cabeça dura, mas também... Tem gente que é reservado, talvez até falta de informação mesmo, pelo menos alguma coisa entrou na cabeça deles, né? Alguma curiosidade que eles não sabiam eles mataram. Acho que teve resultado sim. Pode até não ter sido $100 \%$ porque a gente não é expert, mas alguma coisa pelo menos a gente passou pra eles, né? (AM.10)

Esta valorização, mais uma vez, parece girar em torno de uma mística do poder 
da informação, a ponto de um multiplicador relacionar o não recebimento da informação que tinha a dar durante uma oficina sobre gravidez como a razão para uma colega ter engravidado:
a mina dormiu, a mina se jogou lá no canto lá e dormiu. A sala inteira participou menos ela, entendeu?(...) Daí hoje ela tá na minha sala e ela tá grávida, entendeu?(...) Se a menina tivesse participado do bagulho... ela não precisava tá grávida hoje, a não ser que ela quisesse, que ela queira tá grávida, eu não sei se ela quis... (AM.12)

Este aspecto mostrou-se expressivo e preocupante para a equipe coordenadora do projeto. A informação, sem dúvida, é parte importante de uma estratégia para reduzir a vulnerabilidade dos adolescentes. Porém, é ponto crucial da intervenção proposta a superação da idéia de que a informação, ou a falta dela, é o que determina os comportamentos. Encontramos entre os multiplicadores do Virgília, no entanto, uma visão muito próxima ao modelo preventivista tradicional, pautado numa pedagogia unilateral e modeladora.

É curioso e estimulante verificar, contudo, que convive com essa arraigada crença na onipotência da informação o reconhecimento da diferença do modelo pedagógico que se quer usar no projeto preventivo desenvolvido no Virgília em relação ao modelo mais tradicional, que eles identificam com o do próprio ensino formal da escola.

A gente não pode nem criticar muito, falar muito porque se a gente tipo: 'Pô, violão na sala, não dá', se a gente falar isso, eles: 'Pô, ó a professora aí, ó, mesma coisa. (...) ela lendo lá o papel, tipo, parecia um professor, sabe? E a nossa função não é isso, a nossa função é integrar todo mundo, pra conversar, pra ter um diálogo legal. (AM.7)

Eu gostei, eu gosto de ser multiplicadora... Eu acho legal o sentido da gente, a gente na oficina, a gente discutir entre a gente o que cada um pensa. É legal você perceber a opinião das outras pessoas. Às vezes você pensa de um jeito e você vê outras que pensam de um jeito totalmente diferente, e aí você vai procurar saber, 'mas porquê, talvez ela veja esse lado?' Aí você vai começa a ver um outro lado também. Acho essa parte da discussão muito legal. (AM.3)

Outro aspecto muito relevante que emergiu dos depoimentos foi a presença uma ação positiva do multiplicador para além dos espaços formais de sua atuação. Os multiplicadores se tornaram, efetivamente, uma referência para pares.

... eu tava no supermercado fazendo compras com os meus pais, aí a menina veio me perguntar, ela pegou: 'Luciana, eu queria te fazer uma pergunta...' eu nem lembrava da menina direito, aí ela pegou e falou: 'Sabe o que que é, eu queria saber o nome da pílula do dia seguinte.' Aí eu peguei: 'Ah, a pílula.. Aí eu peguei e lembrei que eu tinha anotado até o nome, mas eu não sabia onde tava na hora, né? E nisso, como tava no final de ano, meu pai tinha passado aqui pra me pegar, buscado a minha mãe, a gente ia no mercado, aí tava o meu material. Aí lá vai a Luciana 
procurar lá no carro pra ver se achava o papel. Aí eu achei, aí ela agradeceu, ela falou que gostava do projeto, que não sei o que. Eu até falei pra ela vir quando começasse o ano. Mas eu achei muito engraçado.' (AM.7)

...difícil uma menina falar sobre a primeira vez dela com um garoto, né? (...) ela chegou pra mim e perguntou: 'Puta, meu, meu namorado tá meio que forçando a barra... E aí, o quê é que eu faço?' E aí a gente começou a conversar (...) No outro dia a menina chegou: 'Não, porque eu terminei com o meu namorado, tal, eu tô super bem...', isso porque ela era apaixonada pelo moleque, sabe? Desde pequena, um moleque mais velho, tal. Daí ela terminou com o moleque e falou: 'Não, eu tô super bem, não sei o que, não sei o que, já tô até a fim de uma pessoa...' Daí um mês depois ela começou a ficar com o moleque... (AM.12)

Foi relatado, também, que esta rede de comunicação transborda os muros da escola e chega à casa, à família:
Uma coisa que eu falei pra minha mãe foi a camisinha feminina, que ela não tinha visto ainda. Levei, daí ela perguntou como é que se usava aí eu expliquei pra ela. Também expliquei alguma coisa sobre aids que ela também não sabe muita coisa. (AM.8)

O reconhecimento dos alunos como multiplicadores por parte da escola ocorreu de forma variada, mas de uma maneira geral os AM perceberam um reconhecimento por parte dos professores.
A professora, tipo, de matemática.... mas tipo, ela nunca tinha sido minha professora ano passado. Ela: 'Ah, você é multiplicador, né, Ricardo? Então vem cá.' Eu levantei: 'O quê foi professora?’, 'Não, vem cá, explica pra sala (...)'. (AM.12)

Alguns multiplicadores entrevistados já não eram mais alunos da escola, mas permaneceram ligados ao grupo depois que concluíram seus estudos $e$ continuam visitando as oficinas semanais de capacitação dos multiplicadores, mostrando o valor não negligenciável que o projeto teve em suas vidas. Outros, já antecipando a mesma necessidade, afirmaram um mesmo vínculo com a atividade.

\footnotetext{
Não, eu acho que eu só vou sair do grupo o dia que vocês não tiverem mais, ou então... se vocês não tiverem mais eu procuro vocês, não tem problema (risos). Mas assim, tipo, só quando não der mesmo pra mim ficar de verdade. Do contrário não, mesmo que eu saia do colégio, tal, se eu tiver tempo eu quero tá disponível pra trabalhar com vocês, que eu gosto muito disso, é uma coisa que eu torço assim, eu chego: 'Puta, quarta-feira tem que chegar logo, tal, vai ter oficina.' (AM.2)
}

\section{Conclusão}

O protocolo de investigação entre os pares demonstrou a efetividade da estratégia de multiplicação na escola estudada. As atividades erambem 
conhecidas dos alunos da escola, sendo os multiplicadores claramente identificados pelos pares. O trabalho mostrou-se relativamente bem compreendido e positivamente avaliado

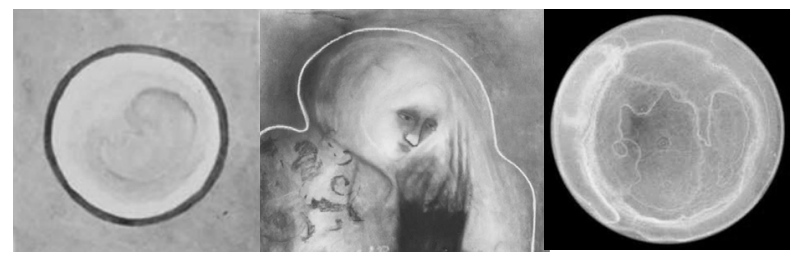
pela grande maioria, que defende que as atividades de prevenção na escola devam ser conduzidas por outros jovens. $\mathrm{O}$ ganho que os alunos mais identificaram com a participação nas oficinas é a possibilidade de discussão dos temas propostos. Foram detectados, contudo, importantes desafios para seu aprimoramento: superar a dificuldade de sentirse à vontade para expor livremente suas opiniões e posições no espaço da oficina; garantir o respeito às opiniões e o sigilo quanto às questões discutidas; melhorar a imagem do multiplicador e a confiança nele por seus pares; diversificar as atividades do multiplicador na escola; $e$ ampliar a identificação dos objetos de trabalho dos multiplicadores para além de DST/AIDS e uso de camisinha.

Em relação ao protocolo de auto-avaliação dos multiplicadores, destacaramse como achados a diversidade de perfis, indicando que, aparentemente, a atividade é atraente não para um determinado tipo de aluno, mas para uma ampla gama de sujeitos. A busca pessoal de informação mostrou ser elemento central na motivação pessoal dos multiplicadores para procurarem o projeto, $e$ deve ser considerada na construção de iniciativas similares. Ainda como traço motivador, a facilidade de comunicação ou a necessidade de superar dificuldades nessa área mostraram-se, também, elementos fundamentais na adesão dos multiplicadores. Veicular informação foi considerado pelos multiplicadores uma de suas mais importantes tarefas (e também a que confere prestígio e "capital social").

Um importante resultado do trabalho com os multiplicadores foi a formação de uma rede informal de comunicação organizada em torno dos multiplicadores na escola e com efeitos que se estendem para além dela. Uma adequada e conseqüente consideração das características dessa rede e seus potencializadores é um trabalho que pode trazer importantes aportes às ações de prevenção baseadas na redução de vulnerabilidade.

O principal desafio detectado neste protocolo consiste na aculturação do aluno multiplicador no modelo preventivo orientado pela redução de vulnerabilidade. Com efeito, observou-se, no cotidiano das vivências dos multiplicadores, uma tensão entre o modelo da transmissão unilateral da informação e uma pedagogia construtivista, baseada na discussão multilateral entre os pares, proposta pelo projeto. Esta tensão surgiu no discurso dos entrevistadores como freqüentes contradições entre a imagem ideal do multiplicador como aquele que instrui e esclarece (e, enquanto tal, é socialmente valorizado) e a efetiva construção de espaços de discussão, de trocas entre iguais, diferenciado do próprio modelo pedagógico rotineiro da escola. Isso precisa ser explicitado e trabalhado no processo de formação dos multiplicadores, de forma a potencializar a construção negociada e criativa de respostas sociais, ao invés da reprodução acrítica dos modelos preventivistas tradicionais.

Os dados que produzimos no estudo quantitativo e qualitativo podem ainda trazer maiores informações e ampliar a extensão de sua validade interna $e$ externa, se submetidos a tratamentos estatísticos e interpretativos mais 
avançados. Não restou dúvida, no entanto, que um tratamento descritivo cuidadoso $e$ atento já foi capaz de revelar aspectos valiosos sobre a intervenção preventiva em questão, com a vantagem de refletir mais fidedignamente as possibilidades que os educadores da rede escolar vão encontrar no dia a dia do desenvolvimento de seus projetos. As possibilidades de ampliação do poder intelectivo que tratamentos mais sofisticados podem dar a materiais desse tipo sugerem, no entanto, o estabelecimento de parcerias entre universidade, ONGs e rede de serviços no desenho e monitoramento de trabalhos preventivos em escolas.

Os diversos aportes trazidos por este processo de avaliação demonstram, em síntese, a viabilidade de uma estratégia de redução de vulnerabilidade no espaço escolar, com uma significativa mudança do papel do aluno multiplicador, se comparado com propostas similares no paradigma comportamentalista.

É certo que nossas avaliações demonstraram uma série de fragilidades $e$ desafios que precisam ser enfrentados. Em primeiro lugar, completando esta avaliação com a inquirição mais detalhada da perspectiva de dois outros grupos de fundamental importância no processo: os professores e os pais ou familiares responsáveis, que podem contribuir com ricos subsídios sobre processos $e$ resultados de ações preventivas. Ainda assim, já há subsídios suficientes para aperfeiçoamentos da intervenção experimental no Virgília e de outras experiências similares. Ficou claro, por exemplo, que apesar de o quadro da redução de vulnerabilidade apoiar-se em deslocamentos conceituais importantes em relação aos fundamentos e métodos preventivistas mais tradicionais, ainda dispomos de poucos instrumentos e tecnologias apropriados a tais deslocamentos. Nossas oficinas de capacitação e multiplicação e nossas intervenções, de modo geral, ainda são excessivamente ancoradas na abordagem higienista e individualista da redução de comportamentos de risco. É preciso, em especial, construir metodologias de capacitação mais efetivas no convite aos protagonistas da ação preventiva a uma perspectiva mais radicalmente dialógica e construtivista na interação com seus pares. Se já foi um grande avanço produzir discussão, e não simplesmente informação, há ainda muito o que caminhar na mobilização e envolvimento social internos ao grupo.

Não nos pareceu haver qualquer recusa, por parte da comunidade escolar $e$ dos alunos multiplicadores, da estratégia de redução de vulnerabilidade, mas sim uma incompleta compreensão da extensão do convite que esta faz à construção de respostas sociais. Todo o capital social que os multiplicadores percebem acumular quando se apropriam de informações e as veiculam, quando têm oportunidade de troca e reflexão ou quando ampliam $e$ enriquecem sua sociabilidade, precisa deixar de ser entendido como uma estrita aquisição individual para que uma estratégia de redução de vulnerabilidade se implante mais radical e produtivamente. É preciso que percebam que esta aquisição já é resultado de uma produção social e que, quanto mais amplamente se distribua e reproduza, maiores serão seus potenciais transformadores. Para tanto, é preciso que os multiplicadores deixem de representar (a prevenção) perante seus pares e se coloquem como representantes de seus pares frente ao desafio da prevenção.

Nesse sentido, e apoiando-nos no bem sucedido protagonismo dos AM, é fundamental rever as formas de sua captação, capacitação, adesão e atuação,

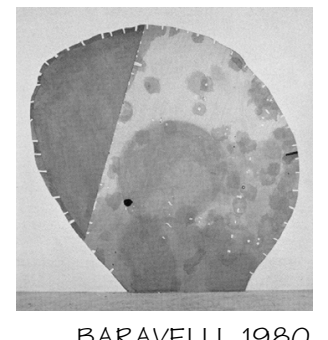

BARAVELLI, 1980 
buscando não apenas desconstruir as noções e práticas tradicionais de prevenção e redução de risco, mas o próprio sentido de representação daqueles que se propõem a protagonizar a reconstrução das ações preventivas. Para isso, é preciso ampliar e recriar as formas de comunicação entre os diferentes sujeitos envolvidos, renovar as formas de expressão de identidades, valores, projetos, diversificar e interligar redes sociais, potencializando suas trocas e sinergismos, e transformar ativamente seus contextos de intersubjetividade, a começar por aqueles construídos $e$ constituídos na e pela escola.

\section{Referências}

AYRES, J.R.C.M. O jovem que buscamos e o encontro que queremos ser: a vulnerabilidade como eixo de avaliação de ações preventivas do abuso de drogas, DST e AIDS entre crianças e adolescentes. In:

TOZZI, D., SANTOS, N.L., AMARO, C.M., ALMEIDA, E., SILVA, E.J., PEREIRA, M.L. (Orgs.) Papel da educação na ação preventiva ao abuso de drogas e às DST/AIDS. São Paulo: Fundação para o Desenvolvimento da Educação, 1996a. p. 15-24. (Série Idéias, 29).

AYRES, J.R.C.M. Educação preventiva e vulnerabilidade às DST/AIDS e abuso de drogas entre escolares: como avaliar a intervenção? In: TOZZI, D., SANTOS, N.L., AMARO, C.M., ALMEIDA, E., SILVA, E.J., PEREIRA, M.L. (Orgs.) Papel da educação na ação preventiva ao abuso de drogas e às DST/AIDS. São Paulo: Fundação para o Desenvolvimento da Educação, 1996b. p.25-41 (Série Idéias, 29).

AYRES, J.R.C.M. Vulnerabilidade dos jovens ao HIV/AIDS: a escola e a construção de uma resposta social. In: SILVA, L.H. (Org.) A escola cidadã no contexto da globalização. Petrópolis: Vozes, 1998. p. 413-23.

AYRES, J.R.C.M., FRANÇA JÚNIOR, I., CALAZANS, G.J., SALETTI FILHO, H.C. Vulnerabilidade e prevenção em tempos de Aids. In: BARBOSA, R. M., PARKER, R. G. (Orgs.) Sexualidades pelo avesso: direitos, identidade e poder. São Paulo: Ed. 34, 1999. p. 49-72.

DARROCH, J.E., LANDRY, D.J., SINGH, S. Changing emphases in sexuality education in U.S. public secondary schools, 1988-1999. Fam. Plann. Perspect., v.32, n.5, p.204-11, 2000.

DICLEMENTE, R. Adolescents and AIDS: a generation in jeopardy. Newbury Park: Sage, 1992.

FERNÁNDEZ COSTA, S., JUÁREZ MARTÍNEZ, O., DÍEZ DAVID, E. Prevención del SIDA en la escuela secundaria: recopilación y valoración de programas. Rev. Esp. Salud Publica, v.73, n. 6, p. 687-96, 1999.

FONSECA, A. Prevenção às DST/AIDS no ambiente escolar. Interface - Comunic., Saúde, Educ., v.6, n.11, p.71-87, 2002.

GAO, Y., LU, Z.Z., SHI, R., SUN, X.Y., CAI, Y. AIDS and sex education for young people in China. Reprod. Fertil. Dev., v.13, n.7-8, p.729-37, 2001.

HOVELL, M., BLUMBERG, E., SIPAN, C., HOFSTETTER, C.R., BURKHAM, S., ATKINS, C., FELICE, M. Skills training for pregnancy and AIDS prevention in Anglo and Latino youth. J. Adolesc. Health, v.23, n.3, p.139-49, 1998.

KIRBY, D., KORPI, M., ADIVI, C., WEISSMAN, J. An impact evaluation of project SNAPP: an AIDS and pregnancy prevention middle school program. AIDS Educ. Prev., v.9, n.1, Suppl, p.44-61, 1997.

KIRBY, D., SHORT, L., COLLINS, J., RUGG, D. School-based programs to reduce sexual risk behaviors: 
a review of effectiveness. Public Health Reports, v.109, n.3, p.339-60, 1994.

MANN, J., TARANTOLA, D.J.M. (Eds.) AIDS in the world II. New York: Oxford University Press, 1996.

MANN, J., TARANTOLA, D.J.M., NETTER, T.W. (Orgs.) A AIDS no mundo. Rio de Janeiro: Relume-Dumará, 1993.

MOORE, S., ROSENTHAL, D., MITCHELL, A. Youth, AIDS and Sexually Transmitted Diseases. New York: Routledge, 1996.

NEMES, M.I.B. Avaliação em saúde: questões para os programas de DST/AIDS no Brasil. Rio de Janeiro: ABIA, 2001 (Coleção ABIA - Fundamentos de Avaliação, 1).

NOVAES, H.M.D. Avaliação de programas, serviços e tecnologias em saúde. Rev. Saúde Pública, v.34, n.5, p. 547-59, 2000.

PAIVA, V. Fazendo arte com camisinha: sexualidades jovens em tempos de aids. São Paulo: Summus, 2000.

PARKER, R. Na contramão da aids: sexualidade, intervenção, política. Rio de Janeiro: ABIA, 2000.

RICKERT, V.I., JAY, M.S., GOTTLIEB, A. Effects of a peer-counseled AIDS education program on knowledge, attitudes, and satisfaction of adolescents. J. Adolesc. Health, v.12, n.1, p.38-43, 1991.

SCHORT, R. Teaching safe sex in school. Int. J. Gynaecol. Obstet., v.63, Suppl 1, p.147-50, 1998.

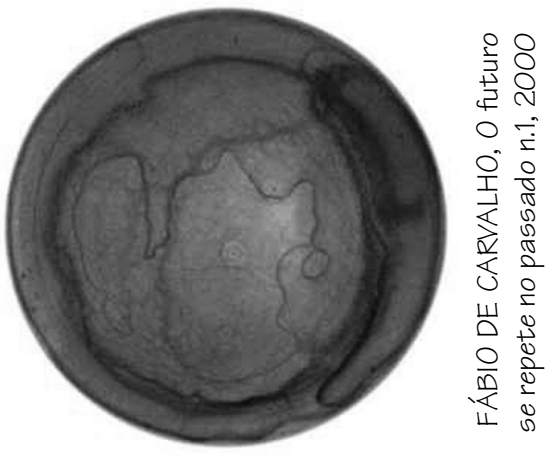

AYRES, J. R. C. M. Adolescencia y SIDA: evaluación de una experiencia de educación preventiva entre pares, Interface - Comunic, Saúde, Educ, v.7, n.12, p.113-28, 2003.

Las acciones preventivas de HIV/SIDA dirigidas a la superación de los límites de las intervenciones de carácter comportamentalista, incorporando preocupaciones con los determinantes socioculturales de esos comportamientos, constituyen hoy una necesidad y, al mismo tiempo, una laguna. El presente artículo trata de estudio de prevención en el ambiente escolar, basado en estrategia de reducción de vulnerabilidad. Constituye un estudio de caso, de corte cuanti-cuali, que, en el contexto de esta estrategia, evalúa el trabajo de prevención de SIDA desarrollado por alumnos multiplicadores en una escuela provincial de enseñanza media en la periferia de la ciudad de São Paulo. Entre los resultados, se destacan: la efectividad de la propuesta, con amplia aceptación y aprovechamiento favorable por los alumnos de la escuela; el perfil diversificado del alumno multiplicador voluntario; y la tensión entre modelos cognitivo-comportamentalistas y social-constructivistas en los procesos educativos concretamente operados por los multiplicadores. Se concluye por la posibilidad e interés de la acción de alumnos multiplicadores en la perspectiva de las estrategias de reducción de vulnerabilidad, apuntando la necesidad de desarrollar mecanismos de captación y capacitación capaces de problematizar y superar la tensión apuntada.

PALABRAS CLAVE: SIDA; prevención; escuela; vulnerabilidad; adolescencia; evaluación. 